\title{
Gender differential on characteristics and outcome of leprosy patients admitted to a long-term care rural hospital in South-Eastern Ethiopia
}

\author{
José M Ramos ${ }^{1,2,3^{*}}$, Miguel Martínez-Martín ${ }^{4}$, Francisco Reyes ${ }^{1}$, Deriba Lemma ${ }^{1}$, Isabel Belinchón ${ }^{5}$
} and Félix Gutiérrez ${ }^{3,6}$

\begin{abstract}
Introduction: In previous studies, women are less aware of causation and symptoms of leprosy and have less access to health care coverage than men, thus contributing to their delay in seeking for treatment. We assess the gender differences in leprosy cases admitted to a rural referral hospital in Ethiopia for 7 and a half years.

Methods: Retrospective data of the leprosy patients admitted to referral hospital were collected using leprosy admission registry books from September 2002 to January 2010. Variables were entered in an Excel 97 database.

Results: During the period of study, 839 patients with leprosy were admitted; 541 (64.5\%) were male, and 298 (35.6\%) female. Fifteen per cent of female patients, and $7.3 \%$ of male patients were paucibacillary leprosy cases while $84.8 \%$ of female patients and $92.7 \%$ of males were multibacillary leprosy cases $(p<0.001)$. Female leprosy patients were younger than male ones (median: 36 versus 44 years) $(p<0.001)$. In the multivariate analysis, age (odds ratio [OR]: 0.97; 95\% confidence interval [Cl]: 0.96-0.98; $\mathrm{p}<0.001$ ), admission for cardiovascular diseases (OR: 7.6, 95\% Cl: 1.9-29.3; $p=0.004$ ), admission for gastroenteritis (OR: 14.0; 95\% Cl: 1.7-117; $p=0.02$ ), admission from out patients clinic (OR: 2.04; 95\% Cl: 1.1-4.01; $\mathrm{p}=0.02$ ), and mortality as final outcome (OR: $3.1,95 \% \mathrm{Cl}$ : 1.2-8.0; $\mathrm{p}=0.02$ ) were independently associated with female gender.

Conclusions: Female patients with leprosy admitted to hospital were younger, had a different profile of admission and a higher mortality rate than male ones.
\end{abstract}

Keywords: Leprosy, Gender, Sex, Female, Hospital, Ethiopia

\section{Introduction}

Leprosy is a chronic disease with low-grade infectivity caused by Mycobacterium leprae, that can lead to deformities, physical handicap, and social stigma [1]. During the 1990s and 2000s, leprosy services were intensified in a World Health Organisation (WHO) stimulated effort for reducing the burden of disease in many endemic countries. A consequence of this is that the number of registered leprosy cases has decreased from 5351408 cases in 1985 to 926259 cases in 1996 and 244796 cases in 2009 [2-4]. The introduction of

\footnotetext{
* Correspondence: jramosrincon@yahoo.es

'Gambo General Rural Hospital, Shashemane, Ethiopia

${ }^{2}$ Service of Internal Medicine, Hospital General Universitario de Alicante, Pintor Baeza, Alicante 12 03010, Spain

Full list of author information is available at the end of the article
}

multi-drug therapy (MDT) made possible that leprosy patients could be diagnosed, treated and followed-up in outpatient clinics. However, referral centres continue to play a key role in providing specialized services for patients with complications of the disease, such as leprosy reaction, neuropathy or skin ulcer, as well as in the prevention of disabilities and rehabilitation. Referral centres that are part of the general health-care system have also been crucial in helping primary care [4].

In two cohorts of newly detected leprosy patients in Bangladesh (The Bangladesh Acute Nerve Damage Study [BANDS]) and Ethiopia (ALERT MDT Field Evaluation Study [AMFES]), there were fewer women diagnosed of leprosy than men (ratio female/male 0.6) [5]. Moreover, women are less aware of causation and symptoms of leprosy and have less access to health care 
coverage than men, thus contributing to their delay in seeking for treatment [6-8]. Thus, understanding gender differences in clinical presentation, type of leprosy, and access to health of leprosy patients is important [9]. Also, female leprosy patients suffer more isolation and rejection from society than males [1,10-12].

In this study, we analyse gender differences in clinical and epidemiological characteristics and outcomes of leprosy patients admitted to a long-term care rural referral hospital in South-eastern Ethiopia.

\section{Methods}

\section{Setting}

The Gambo Rural Hospital (GRH) is a rural hospital in Ethiopia (in the Oromiya region), which is a referral centre in the programme of leprosy care in the country according to the guidelines of Tuberculosis and Leprosy Prevention and Control Programme (TLPCP) $[13,14]$. The GRH is located in West-Arsi zone, $250 \mathrm{Km}$ southeast of Addis Ababa. Most of the population live in a rural setting and work in agriculture and farming. In 1961 the Leprosy Centre in Gambo begins its work. Later on (1966-1970), the National Policy for Leprosy Services changes from Leprosy Settlement to Leprosy Control Units or Stations. Gambo Leprosy Centre becomes an Integrated Health Unit catering to all health needs, including leprosy patients, with a 49 beds dispensary. In 1985, the Gambo Leprosy Control Centre changes its name to GRH. Several leprosy cases treated in GRH continued living around the hospital in Gambo leprosy village (about 250 families).

The diagnosis of leprosy is usually made with clinical findings according to TLPCP $[9,10]$. According of TLPCP, criteria for admission are severe erythema nudoso leprosum (ENL) reaction, deep skin ulcer, red and/or painful eye, pregnancy, tuberculosis or any other severe infection, age younger than 12 , recent history of peptic ulcer in the stomach or duodenum, history of diabetes, general illness with fever, patients who did not improve during a previous course of treatment and patients who improved during previous course, but who develop a reaction for the third time $[13,14]$.

In Ethiopia there is a main referral hospital, ALERT Hospital, in Addis Abeba where patients were transferred from different first level leprosy care and from peripheral referral leprosy hospitals [15]. There are 5 referral leprosy hospitals in Ethiopia and GRH is one of them.

All leprosy patients with medical and surgical problems who need hospital admission related or not with leprosy are admitted to the leprosy ward in GRH. The patients stay in hospital until recovery of their problems. The cost of hospitalization is free for them. The food is provided by the hospital. After being discharged, the patients may continue attending the GRH clinic or are transferred to other clinics near their homes.

\section{Study design and data collection}

Diagnosis of leprosy is usually made in the GRH with clinical examination according to TLPCP [13,14]. Patients who are diagnosed as new or old leprosy cases at GRH are: 1) admitted to hospital in the case of seriously ill leprosy patients, 2) registered at the GRH leprosy clinic or 3) referred to leprosy clinics near their home. A retrospective data collection from all the patients diagnosed of leprosy and admitted to the leprosy ward was done using the admission registry book. Patients were classified according to the number of leprosy skin lesions and the result of the skin smear examination as: multibacillary (MB) leprosy (six or more skin lesions or less than six skin lesions which have a positive slit skin smear result) or paucibacillary (PB) leprosy (one to five leprosy skin lesions $[13,14]$.

The health workers completed the admitting forms, which included variables of age, sex, place of residence, case definitions, WHO classification of leprosy (MB or PB leprosy), origin of admission, length of hospital stay, diagnosis during admission, and outcome.

Case definitions were: (1) new case: a patient with $\mathrm{MB}$ or PB leprosy who has never received treatment for leprosy before, (2) a patients who relapses after MDT: a patient properly treated with a complete course of MDT, but who returns to the health service and is found to have active leprosy again; (3) return after withdrawal: an MB patient who returns for treatment, after having missed more than 3 four-weekly doses of MDT; and (4) transfer in: a patient who started treatment in one health setting and moved to another to continue treatment. Origin of admission: field (if the patients was admitted from other leprosy clinic); outpatients (OPD) department (if the patients was admitted from the OPD department). Diagnosis during admission was made using standardised definitions. Definitions of outcome during admission: (1) improved: a patient who has improved within the admission period, (2) died: a patients who dies of any cause, (3) not improvement: a patient who does not improve, or (4) run away: a patient who leaves voluntarily the hospital.

The period analysed in the study began in September 2002 and ended in January 2010, (seven and a half years). Re-admission data were only available for admissions from $1^{\text {st }}$ December 2004 to $31^{\text {st }}$ January 2010. The ethics committee approvals were obtained from the local Research and Publication Committee of the GRH, and Health Unit and Ethical Review Committee of the Ethiopian Catholic Secretary.

\section{Statistical analysis}

Epidemiological and clinical data were entered in an Excel 97 database. Statistical analysis were performed with the use of SPSS software, version 12. Continuous 
variables are given as median, range, and interquartile range (IQR). Chi-square test was used for comparison between two groups of subjects (male and female), Fisher's exact test was used in the case the sample size of patients wasn't large enough, and Kruskal-Wallis test, a nonparametric test, was used to compare the significance of the difference between the distributions of two independent samples. Each category was analysed in a univariate way. Univariate predictors with p-value $<0.25$ were included in a logistic regression model to identify independent variables associated with gender by odds ratio (OR) with a 95\% confidence interval (CI).

\section{Results}

In the seven and a half years period, 839 patients with leprosy were admitted to GRH with an average of 100 cases per year. Among them, 541 (64.5\%) were male, and 298 (35.6\%) female. The male/female ratio of admitted patients was 1.8. Two hundred and forty four (29.1\%) patients were living in the catchment area of the GRH. Female leprosy patients were living in the catchment area more than male leprosy patients $(37.6 \%$ versus. $24.4 \%, \mathrm{p}<0.001)$. The median age of study population was 40 years (IQR: 25 - 55). Twenty-seven (3.2\%) were children (under 15 years old). Female leprosy patients were younger (median age: 36 years) than male ones (median age: 44 years; $\mathrm{p}<0.001$ ) (Table 1). Forty-seven per cent in the female group, and $35.9 \%$ in the male group were included in the 19 to 35 age interval $(\mathrm{p}=0.005)$, and $39.9 \%$ of female patients, and $55.5 \%$ of male patients were older than 35 year-old $(\mathrm{p}<0.001)$.

Data from re-admission were only available for 519 cases. There were $84(16.2 \%)$ cases of readmission without differences by gender. The median of readmissions per patient was 2 times (range: $2-8$ ). The main characteristics of these individuals by gender are shown in Table 2. Thirty nine percent of female lived and $24.4 \%$ of male lived in the catchment area $(\mathrm{p}<0.001)$. Fifteen per cent of female and $7.3 \%$ of male were PB leprosy cases while $84.8 \%$ of female, and $92.7 \%$ of male were MB leprosy cases $(\mathrm{p}<0.001)$. The prevalence of new $M B$, and new $\mathrm{PB}$ cases was similar in women and men $(16.6 \%$ versus $13.2 \%$, and $2.0 \%$ versus $1.1 \%$, respectively). However, the prevalence of old MB cases was significantly lower in female $(68.2 \%)$ than in male ones $(79.6 \%)$, with old $\mathrm{PB}$ cases being more common in female ones $(13.2 \%)$ than in male $(6.1 \%)(\mathrm{p}=0.001)$. There was no difference by gender in the prevalence of patients on MDT. Female leprosy patients were admitted from the OPD in $95.6 \%$ of the cases, and from the "field" in only $4.4 \%$; among male leprosy patients, admission was made from the OPD in $93.8 \%$, and from the "field" in $8.7 \%(\mathrm{p}=0.03)$.

The main diagnosis after discharge was neuropathic skin ulcer $(56.2 \%)$. The diagnosis of neuropathic skin ulcer was performed in $48.3 \%$ of women and $60.5 \%$ of men $(\mathrm{p}=0.001)$. The other mainly diagnoses during the admission were: reversal reaction, neuritis, osteomyelitis, ENL, and lower respiratory tract infection without differences by gender as shown in Table 3. Differences of prevalence between female and male were found in diagnosis of cases not related with leprosy, such as cardiovascular disease $(3.4 \%$ versus $0.6 \% ; \mathrm{p}=0.004)$ or gastroenteritis $(2.8 \%$ versus $0.1 \%$; $\mathrm{p}=0.002)$, being the prevalence of these diseases very low in the sample.

The median length of hospital stay was 65 days (IQR: 36-111) (Table 1). There was no difference between both groups. The majority of patients recovered uneventfully (90.6\%), with no statistical differences between men and women. Only $4.6 \%$ of the sample was referred to other hospitals. The hospital mortality was low (2.8\%), slightly higher in female than in male patients (4.3\% versus $2.0 \% ; \mathrm{p}=0.07$ ). Other outcomes are shown in Table 3.

In the multivariate analysis, age (OR: 0.97; 95\% CI: 0.96-0.98; $\mathrm{p}<0.001$ ) was inversely associated with female gender, in contrast admission from the OPD (OR: 2.4, 95\%: CI 1.1-4.0; $\mathrm{p}=0.03$; versus field admission), and mortality as final outcome (OR: 3.1, 95\% CI: 1.2-8.0; $\mathrm{p}=0.02$ ) were directly associated with female gender (Table 4).

\section{Discussion}

In Ethiopia, since the introduction of MDT for leprosy patients, leprosy control was incorporated as an aim within the general health service system [7]. A referral system could play a crucial role in ensuring the quality of services in an integrated leprosy control programme $[13,14]$. This study analyzed inpatients with leprosy in a rural referral hospital and found significant differences by gender.

Table 1 Median, range and interquartile range (IQR) of age and days of admission in female and male leprosy patients

\begin{tabular}{|c|c|c|c|c|c|c|c|c|}
\hline & \multirow[t]{2}{*}{ Missing } & \multicolumn{2}{|c|}{ Total } & \multicolumn{2}{|c|}{ Male } & \multicolumn{2}{|c|}{ Female } & \multirow[t]{2}{*}{$P$ value } \\
\hline & & Median & Range/IQR & Median & Range/IQR & Median & Range/IQR & \\
\hline Age, years & M:O; F:0 & 40 & $4-81 / 25-55$ & 44 & $9-81 / 28-57$ & 36 & $4-77 / 24-50$ & $<0.001$ \\
\hline Duration of hospital stay, days & M: 16; F:13 & 65 & $2-550 / 36-111$ & 68 & $2-550 / 40-108$ & 60 & $1-490 / 28-113$ & 0.69 \\
\hline
\end{tabular}

M: male; F: female. 
Table 2 Main epidemiological and clinical characteristics, and outcome in female and male leprosy patients

\begin{tabular}{|c|c|c|c|c|c|c|c|c|c|}
\hline \multirow[t]{2}{*}{ Variables } & \multirow[t]{2}{*}{ Missing } & \multicolumn{2}{|c|}{ Total } & \multicolumn{2}{|c|}{ Male } & \multicolumn{2}{|c|}{ Female } & \multirow[t]{2}{*}{ Chi- square value } & \multirow[t]{2}{*}{$P$ value } \\
\hline & & $\mathrm{N}$ & $\%$ & $\mathrm{~N}$ & $\%$ & $\mathrm{~N}$ & $\%$ & & \\
\hline Origin & $\mathrm{M}: 0 ; \mathrm{F}: 0$ & & & & & & & 16.2 & $<0.001$ \\
\hline Catchment area & & 244 & 29.1 & 132 & 24.4 & 112 & 37.8 & & \\
\hline Outside catchment area & & 595 & 70.9 & 409 & 75.6 & 186 & 62.2 & & \\
\hline Age & $\mathrm{M}: 0 ; \mathrm{F}: 0$ & & & & & & & & \\
\hline$<18$ & & 89 & 10.6 & 47 & 8.7 & 42 & 14.1 & 5.88 & 0.020 \\
\hline $19-35$ & & 331 & 39.5 & 194 & 35.9 & 137 & 46.0 & 8.21 & 0.005 \\
\hline$>35$ & & 419 & 49.9 & 300 & 55.5 & 119 & 39.9 & 18.12 & $<0.001$ \\
\hline Re-admission & M: 204; F: 114 & & & & & & & 0.09 & 0.82 \\
\hline Yes & & 84 & 16.2 & 53 & 15.8 & 31 & 16.8 & & \\
\hline No & & 435 & 83.8 & 282 & 84.2 & 153 & 83.2 & & \\
\hline WHO classification & $\mathrm{M}: 1 ; \mathrm{F}: 2$ & & & & & & & 13.49 & $<0.001$ \\
\hline PB & & 84 & 10.0 & 39 & 7.3 & 45 & 15.2 & & \\
\hline$\overline{M B}$ & & 752 & 90.0 & 501 & 92.7 & 251 & 84.8 & & \\
\hline On MDT & $\mathrm{M}: 1 ; \mathrm{F}: 2$ & & & & & & & 2.68 & 010 \\
\hline Yes & & 132 & 15.7 & 78 & 14.3 & 55 & 18.6 & & \\
\hline No & & 710 & 84.3 & 461 & 85.7 & 237 & 81.4 & & \\
\hline Old or New cases & $\mathrm{M}: 1 ; \mathrm{F}: 2$ & & & & & & & & \\
\hline New MB & & 120 & 14.3 & 71 & 13.2 & 49 & 16.6 & 1.81 & 0.21 \\
\hline New PB & & 12 & 1.4 & 6 & 1.1 & 6 & 2.0 & 0.02 & 0.99 \\
\hline Old MB & & 632 & 75.6 & 430 & 79.6 & 202 & 68.2 & 13.41 & $<0.001$ \\
\hline Old PB & & 72 & 8.6 & 33 & 6.1 & 39 & 13.2 & 12.13 & 0.001 \\
\hline Admission from & $\mathrm{M}: 0 ; \mathrm{F}: 0$ & & & & & & & 5.39 & 0.03 \\
\hline OPD & & 779 & 92.8 & 494 & 91.3 & 285 & 95.6 & & \\
\hline Field & & 60 & 7.2 & 47 & 8.7 & 13 & 4.4 & & \\
\hline Outcome & M:37; F:21 & & & & & & & & \\
\hline Improved & & 707 & 90.6 & 459 & 91.0 & 248 & 89.6 & 0.49 & 0.56 \\
\hline Referred & & 36 & 4.6 & 25 & 5.0 & 11 & 4.0 & 0.30 & 0.65 \\
\hline Death & & 22 & 2.8 & 10 & 2.0 & 12 & 4.3 & 3.60 & 0.09 \\
\hline Not improved & & 8 & 1.0 & 4 & 0.8 & 4 & 1.4 & 0.29 & 0.62 \\
\hline Voluntary discharged & & 8 & 1.0 & 6 & 1.2 & 2 & 0.7 & 0.05 & 0.80 \\
\hline
\end{tabular}

M: male; F: female; MDT multidrug therapy; MB: multibacillary; PB: paucibacillary; OPD: outpatients department.

Traditionally, the preponderance of male patients over female ones has been reported [5-8]. In the current study, the ratio male/female in admitted leprosy patients (1.8) was slightly lower than the observed in a new cases sample diagnosed in our centre previously (2.1) [16]. This fact agrees with previous studies conducted in other African countries [5,6,8,17]. However there are studies with a similar proportion of men/and women $[18,19]$, and others where the ratio is as high as 3:1 $[20,21]$. In our study the ratio male/female in admitted leprosy patients was 1.8 , however in a recent national demographic survey [22], carried on by the Ethiopian Ministry of Health, the amount of men in an aleatory sample that was representative of almost 18.000 households in the whole country was inferior to the amount of women. In Ethiopia and in Oromiya region, the ratio of men to women was 0.78 and 0.83 , respectively, so, in our study, the rate male/female is not biased toward males.

Female patients admitted were younger than male patients. Arora et al. [20] in a study performed in cases diagnosed in a tertiary care centre in India found leprosy more prevalence in female than in male in the age group ranged 15 to 35 years, suggesting that hormonal imbalance related to pregnancy/puerperium, might play a role. This peak incidence observed in women in the fertile age group has also been reported in other studies [23].

Female patients live in the catchment area more often than male patients, though is not seen in the multivariate analysis. It might be explained by the reason that male patients have more incomes, and they are more likely to afford to travel further to get care. But, this 
Table 3 Diagnosis during hospital admission in female and male leprosy patients

\begin{tabular}{|c|c|c|c|c|c|c|c|c|c|}
\hline & \multirow[b]{2}{*}{ M:2; F:6 } & \multicolumn{2}{|c|}{ Total } & \multicolumn{2}{|c|}{ Male } & \multicolumn{2}{|c|}{ Female } & \multirow[t]{2}{*}{ Chi- square value } & \multirow[t]{2}{*}{$P$ value } \\
\hline & & $\mathrm{N}$ & $\%$ & $\mathrm{~N}$ & $\%$ & $\mathrm{~N}$ & $\%$ & & \\
\hline Infected skin ulcer & & 467 & 56.2 & 326 & 60.5 & 141 & 48.3 & 11.52 & 0.001 \\
\hline Reversal reaction & & 80 & 9.6 & 48 & 8.9 & 32 & 10.9 & 0.80 & 0.40 \\
\hline Neuritis & & 72 & 8.7 & 49 & 9.1 & 23 & 7.9 & 0.30 & 0.64 \\
\hline Osteomyelitis & & 68 & 8.2 & 47 & 8.7 & 21 & 7.2 & 0.10 & 0.81 \\
\hline ENL & & 46 & 5.5 & 29 & 5.4 & 17 & 5.8 & 0.03 & 0.91 \\
\hline LRTI & & 31 & 5.7 & 17 & 3.1 & 14 & 4.8 & 0.50 & 0.32 \\
\hline Cellulitis & & 16 & 1.9 & 9 & 1.7 & 7 & 2.4 & 0.30 & 0.64 \\
\hline Diabetes mellitus & & 13 & 1.6 & 9 & 1.7 & 4 & 1.4 & 0.04 & 0.97 \\
\hline Cardiovascular diseases & & 13 & 1.6 & 3 & 0.6 & 10 & 3.4 & 9.92 & 0.004 \\
\hline Gastroenteritis & & 9 & 1.1 & 1 & 0.2 & 8 & 2.7 & 11.29 & 0.002 \\
\hline Accident & & 7 & 0.8 & 4 & 0.7 & 3 & 1.0 & 0.20 & 0.70 \\
\hline Chronic liver diseases & & 7 & 0.8 & 2 & 0.4 & 5 & 1.7 & 3.1 & 0.06 \\
\hline Tuberculosis & & 6 & 0.7 & 5 & 0.9 & 1 & 0.3 & 0.30 & 0.60 \\
\hline Arrhythmia & & 5 & 0.6 & 4 & 0.7 & 1 & 0.3 & 0.35 & 0.66 \\
\hline Eyes problems & & 5 & 0.6 & 1 & 0.2 & 4 & 1.4 & 3.3 & 0.05 \\
\hline Peptic ulcer & & 5 & 0.6 & 1 & 0.2 & 4 & 1.4 & 3.2 & 0.06 \\
\hline Intestinal parasites & & 5 & 0.6 & 3 & 0.6 & 2 & 0.7 & 0.01 & 0.99 \\
\hline Mental disorders & & 4 & 0.5 & 1 & 0.2 & 3 & 1.0 & 2.5 & 0.12 \\
\hline Neoplasm & & 3 & 0.4 & 3 & 0.6 & 0 & 0.0 & 0.5 & 0.31 \\
\hline Urinary tract infection & & 3 & 0.4 & 3 & 0.6 & 0 & 0.0 & 0.5 & 0.30 \\
\hline Others & & 12 & 1.4 & 7 & 1.3 & 5 & 1.7 & - & - \\
\hline Total* & & 831 & 100 & 539 & 100 & 292 & 100 & - & - \\
\hline
\end{tabular}

M: male; F: female; ENL: erythema nodosum leprosum; LRTI: lower respiratory tract infection.

* Because each patient could have $>1$ diagnosis, the number of cases can be higher than the number of patients.

question is not possible to answer with the type of design of this study.

The prevalence of MB leprosy cases admitted to hospital was lower in the female group than in the male one. However, the effect of WHO leprosy classification was not significant after adjustment for other variables including age. The prevalence of $\mathrm{MB}$ leprosy in male patients has been reported to be higher than in female ones in different series of new cases diagnosed in

Table 4 Variables associated with female gender in a multivariate analysis*

\begin{tabular}{llll}
\hline & OR & $\mathbf{9 5 \%} \mathbf{C l}$ & P value \\
\hline Age & 0.97 & $0.96-0.98$ & $<0.001$ \\
\hline Admission for cardiovascular diseases & 7.6 & $1.9-29.3$ & 0.004 \\
\hline Admission from the OPD & 2.4 & $1.1-4.0$ & 0.03 \\
\hline Admission for gastroenteritis & 14.0 & $1.7-117$ & 0.02 \\
\hline Died as final outcome & 3.1 & $1.2-8.0$ & 0.02 \\
\hline
\end{tabular}

NOTE: OR: odds ratio; $95 \%$ confidence intervals (Cl); OPD: outpatient clinic. * Variables with p-value $<0.25$ in univariate analysis were included in the logistic regression model. They were: origin of patients, age of patients WHO classification, old or new paucibacillary or multibacillary leprosy cases, admission from field or OPD, died as final outcome, and infected skin ulcer, cardiovascular diseases, gastroenteritis, chronic liver diseases, eyes problems, peptic ulcer, and mental disorder as cause of admission. endemic countries such as Nigeria, Indonesia, Brazil, Nepal and Malawi [6,18-21].

Chronic skin ulcers are among the most serious complications of leprosy [24]. In our study, the main diagnosis during admission to hospital was neuropathic skin ulcer in lower extremities associated with infection or osteomyelitis. Neuropathic skin ulcers are one of the most common sequelae of leprosy and can result in large economic and social burden [25,26]. In our study, this diagnosis was less common in women than in men admitted to hospital in the univariate analysis. A descriptive cross-sectional study conducted in 245 leprosy patients with infected ulcers visiting three Ethiopian hospitals (ALERT, Kuyera and GRH) from August 2006 to May 2007 found an incidence of ulcers of $64.1 \%$ in men and $35.9 \%$ in women [24]. Similar results have been reported in other studies $[27,28]$. Britton and Lockwood [29] described this predominance, as true difference between men and women. This is not because of being underdiagnosed in women, but in some countries it was noticed by the delayed presentation of female patients, which results in high deformity.

Admissions for medical problems associated with leprosy, such as leprorreaction, or neuritis were similar in 
the female and male groups. In this regard, admissions for other diagnosis, apparently unrelated to leprosy, such as cardiovascular diseases (p.e. chronic heart failure or stroke) or gastroenteritis were more common in women than in men.

Leprosy per se is not fatal [30], death among active patients can be regarded as an unusual event, in our study approximately 3 percent died. Although the overall death rate in the sample was very low, we observed differences in fatality rates by gender. Fatal cases were more common in women than in men in multivariate analysis, finding that might be related to the comorbidity pattern leading to hospital admission.

Several limitations should be considered in this study. Due to the fact that it was retrospectively conducted with data collected from a registry book, some of our data are incomplete, including co-morbidities and neurological assessments. Moreover, the re-admission rate was recorded in less than two thirds of patients admitted.

\section{Conclusions}

Despite these limitations, we understand that the characteristics of women admitted in our institution are different than in men, they were younger, had a different profile of admission and a higher mortality rate than male ones. However, with our results it is not able to get other conclusions about gender relation with the access to health care coverage, the delay in seeking for care and the isolation and rejection from the society.

\section{Competing interests}

The authors declare that they have no competing interests.

\section{Authors' contributions}

IB did the literature review and wrote the introduction. FR and $D L$ review the cases. JMR and MMM wrote the methods section and carried out the data analysis. JMR, MMM and FG wrote the Results and Conclusions sections. JMR $M M M, D L, I B, F G$, read and approved the final manuscript

\section{Acknowledgements}

We would like to thank the leprosy officers of GRH for collecting the data. We also thank the laboratory staff for their assistance in the microbiological diagnosis of leprosy, and the nursing staff for the care of the patients.

\section{Author details}

${ }^{1}$ Gambo General Rural Hospital, Shashemane, Ethiopia. ${ }^{2}$ Service of Internal Medicine, Hospital General Universitario de Alicante, Pintor Baeza, Alicante 12 03010, Spain. ${ }^{3}$ Department of Clinical Medicine, Universidad Miguel Hernández, Alicante, Spain. ${ }^{4}$ Service of Internal Medicine, Hospital La Princesa, Madrid, Spain. ${ }^{5}$ Service of Dermatology, Hospital General Universitario de Alicante, Alicante, Spain. ${ }^{6}$ Infectious Diseases Unit, Hospital General Universitario de Elche, Alicante, Spain.

Received: 17 March 2012 Accepted: 27 September 2012 Published: 4 October 2012

\section{References}

1. Zodpey SP, Tiwari RR, Salodkar AD: Gender differentials in the social and family life of leprosy patients. Lepr Rev 2000, 71:505-510.
2. Anonymous: Progress towards the elimination of leprosy as a public health problema. Wkly Epidemiol Rec 1996, 71:149-156.

3. Anonymous: Progress towards leprosy elimination. Wkly Epidemiol Rec 1998, 73:153-260.

4. Anonymous: Global leprosy situation, 2010. Wkly Epidemiol Rec 2010 85:337-348.

5. Van Veen $\mathrm{NH}$, Meima A, Richardus $\mathrm{JH}$ : The relationship between detection delay and impairment in leprosy control: a comparison of patient cohorts from Bangladesh and Ethiopia. Lepr Rev 2006, 77:356-365.

6. Peters ES, Eshiet AL: Male-female (sex) differences in leprosy patients in south eastern Nigeria: females present late for diagnosis and treatment and have higher rates of deformity. Lepr Rev 2002, 73:262-267.

7. Rao S, Garole V, Walawalkar S, Khot S, Karandikar N: Gender differentials in the social impact of leprosy. Lepr Rev 1996, 67:190-199.

8. Ebeigbe JA, Kio F: Ocular leprosy in institutionalized Nigerian patients. Ghana Med J 2011, 45:50-53.

9. Kumar RB, Singhasivanon P, Sherchand JB, et al: Gender differences in epidemiological factors associated with treatment completion status of leprosy patients in the most hyperendemic district of Nepal. Southeast Asian J Trop Med Public Health 2004, 35:334-339.

10. Le Grand A: Women and leprosy: a review. Lepr Rev 1997, 68:203-211.

11. de Oliverira MH: The effects of leprosy on men and women: a gender study. Gender Tropical Diseases No. 4. UNDPMord BankWHO Special Programme for Research and Training in Tropical Diseases (TDR. Geneve: Word Health Organization; 1997

12. Erinfolami AR, Adeyemi JD: A case control study of psychiatric morbidities among subjects with leprosy in Lagos, Nigeria. Int J Psychiatry Med 2009, 39:89-99.

13. Federal Ministry of Health: Manual of Tuberculosis and Leprosy and TB/HIV Prevention and Control. 3rd edition. Addis Ababa: Ethio Tikur Printing Press; 2005.

14. Federal Ministry of Health: Manual of Tuberculosis and Leprosy and TB/HIV Prevention and Control. 4th edition. Addis Ababa, Ethiopia: Ethio Tikur Printing Press; 2008.

15. Benbow C, Tamiru T: The experience of self-care groups with people affected by leprosy: ALERT, Ethiopia. Lepr Rev 2001, 72:311-321.

16. Ramos JM, Reyes F, Lemma D, Belinchón I, Gomez JR: Disability profile in leprosy patients' diagnoses in a rural reference leprosy centre in Ethiopia during 1999-2009. Trop Doct 2011, 41:51-53.

17. Meima A, Saunderson PR, Gebre S, et al: Factors associated with impairments in new leprosy patients: the AMFES cohort. Lepr Rev 1999, 70:189-203

18. Varkevisser CM, Lever P, Alubo O, et al: Gender and leprosy: case studies in Indonesia, Nigeria, Nepal and Brazil. Lepr Rev 2009, 80:65-76.

19. Chisi JE, Nkhoma A, Zverev Y, Misiri H, Komolafe OO: Leprosy in Nkhotakota district hospital. East Afr Med 2003, 80:635-639.

20. Arora M, Katoch K, Natrajan M, Kamal R, Yadav VS: Changing profile of disease in leprosy patients diagnosed in a tertiary care centre during years 1995-2000. Indian J Lepr 2008, 80:257-265.

21. Hussein A, Mohammed H, Eltahir A, Sidig A, Gadour MOH: Frequency of neurological deficits in Sudanese lepromatic patients. Sudan JMS 2010 5:17-24

22. Ethiopian Central Statistics Agency: The Ethiopia Demographic and Health Survey (EDHS). Addis Ababa; 2011. http://www.csa.gov.et/docs/EDHS\% 202011\%20Preliminary\%20Report\%20Sep\%2016\%202011.pdf.

23. Lockwood DN, Sinha HH: Pregnancy and leprosy: a comprehensive literature review. Int J Lepr Other Mycobact Dis 1999, 67:6-12.

24. Lema $T$, Woldeamanuel $Y$, Asrat $D$, et al: The pattern of bacterial isolates and drug sensitivities of infected ulcers in patients with leprosy in ALERT, Kuyera and Gambo hospitals, Ethiopia. Lepr Rev 2012, 83:40-51

25. Gahalaut P, Pinto J, Pai GS, Kamath J, Joshua TV: A novel treatment for plantar ulcers in leprosy: local superficial flaps. Lepr Rev 2005, 76:220-231.

26. Barreto JG, Salgado CG: Clinic-epidemiological evaluation of ulcers in patients with leprosy sequelae and the effect of low level laser therapy on wound healing: a randomized clinical trial. BMC Infect Dis 2010, 10:237. 
27. Tiendrebeogo A, Coulibalv I, Sarr AM, Sow SO: Nature and sensitivity of bacteria super infecting plantar ulcers caused by leprosy at the Marchoux Institute, Bamako, Mali. Acta Leprol 1999, 11:153-159.

28. Kunst H: Predisposing factors for recurrent skin ulcers in leprosy. Lepr Rev 2000, 71:363-368.

29. Britton WJ, Lockwood DNJ: Leprosy. Lancet 2004, 363:1209-1219.

30. Shen J, Liu M, Zhou M, Li W: Causes of death among active leprosy patients in China. Int J Dermatol 2011, 50:57-60.

doi:10.1186/1475-9276-11-56

Cite this article as: Ramos et al:: Gender differential on characteristics and outcome of leprosy patients admitted to a long-term care rural hospital in South-Eastern Ethiopia. International Journal for Equity in Health 2012 11:56.

\section{Submit your next manuscript to BioMed Central and take full advantage of:}

- Convenient online submission

- Thorough peer review

- No space constraints or color figure charges

- Immediate publication on acceptance

- Inclusion in PubMed, CAS, Scopus and Google Scholar

- Research which is freely available for redistribution 